\title{
Fruit syndromes in Viburnum: correlated evolution of color, nutritional content, and morphology in bird-dispersed fleshy fruits
}

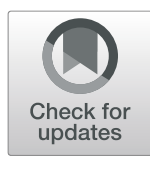

\author{
Miranda A. Sinnott-Armstrong ${ }^{1,2^{*}} \mathbb{D}$, Chong Lee ${ }^{3}$, Wendy L. Clement ${ }^{4}$ and Michael J. Donoghue ${ }^{1}$
}

\begin{abstract}
Premise: A key question in plant dispersal via animal vectors is where and why fruit colors vary between species and how color relates to other fruit traits. To better understand the factors shaping the evolution of fruit color diversity, we tested for the existence of syndromes of traits (color, morphology, and nutrition) in the fruits of Viburnum. We placed these results in a larger phylogenetic context and reconstructed ancestral states to assess how Viburnum fruit traits have evolved across the clade.
\end{abstract}

Results: We find that blue Viburnum fruits are not very juicy, and have high lipid content and large, round endocarps surrounded by a small quantity of pulp. Red fruits display the opposite suite of traits: they are very juicy with low lipid content and smaller, flatter endocarps. The ancestral Viburnum fruit may have gone through a sequence of color changes before maturation (green to yellow to red to black), though our reconstructions are equivocal. In one major clade of Viburnum (Nectarotinus), fruits mature synchronously with reduced intermediate color stages. Most transitions between fruit colors occurred in this synchronously fruiting clade.

Conclusions: It is widely accepted that fruit trait diversity has primarily been driven by the differing perceptual abilities of bird versus mammal frugivores. Yet within a clade of largely bird-dispersed fruits, we find clear correlations between color, morphology, and nutrition. These correlations are likely driven by a shift from sequential to synchronous development, followed by diversification in color, nutrition, and morphology. A deeper understanding of fruit evolution within clades will elucidate the degree to which such syndromes structure extant fruit diversity.

Keywords: Fruit color, Seed dispersal, Plant-animal interactions, Fruit syndromes, Temperate forests, Correlated evolution, Trait evolution

\section{Background}

Fleshy fruits play an essential role in the lives of many plant species, attracting animal dispersers who consume the fruit and carry the seeds away from the parent [1]. This interaction benefits both the plant and animal partners. Animal dispersers receive nutrients and calories by consuming the fleshy pulp of the fruit $[2,3]$, while plants receive dispersal services, enabling gene flow, escape from predation and pathogens, and range expansion $[4,5]$. To communicate that their fruits are ripe and ready to be

\footnotetext{
* Correspondence: miranda.sinnott-armstrong@colorado.edu

'Department of Ecology and Evolutionary Biology and Peabody Museum of

Natural History, Yale University, New Haven, CT 06520, USA

${ }^{2}$ Department of Ecology \& Evolutionary Biology, University of

Colorado-Boulder, Boulder, CO 80309, USA

Full list of author information is available at the end of the article
}

consumed, animal-dispersed plants have evolved visual displays that include the color of individual ripe fruits, clusters of multiple fruits in an infructescence, and/or secondary structures such as immature fruits or pedicels [1, 6]. Although the colors of fruits are certainly important, color is not the only trait that assists plants in signaling to animals the presence of ripe fruit: odor, fruit size, and the size of clusters of fruits (infructescences) are all also important (e.g., [6, 7]).

The primary hypothesis to explain variation in these visual traits has been selection by animals via their perceptual abilities, behavior, and physiology. According to this hypothesis, most fruits can be classified as either "bird fruits" (small, brightly colored) or "mammal fruits" (large, dull in color, possibly with a husk or rind) $[6,8$, 9]. However, this "disperser syndrome hypothesis" is

(c) The Author(s). 2020 Open Access This article is distributed under the terms of the Creative Commons Attribution 4.0 International License (http://creativecommons.org/licenses/by/4.0/), which permits unrestricted use, distribution, and reproduction in any medium, provided you give appropriate credit to the original author(s) and the source, provide a link to the Creative Commons license, and indicate if changes were made. The Creative Commons Public Domain Dedication waiver (http://creativecommons.org/publicdomain/zero/1.0/) applies to the data made available in this article, unless otherwise stated. 
controversial, in part because evidence for selection by dispersers is weak $[6,10-12]$, and because there are strong associations between fruit color and fruit size that may be attributable to the metabolic costs of producing a large fruit rather than selection by animals $[6,13,14]$. Furthermore, birds and mammals are obviously heterogeneous groups with varying visual systems, body sizes, and abilities to manipulate their food, and the simplistic classification into "bird" or "mammal" syndromes does not adequately reflect fruit trait diversity.

An important question when assessing the extent to which putative fruit syndromes relate to animal dispersers is whether aspects of the visual display communicate anything to animals about a fruit's nutritional content. For example, do juicy red fruits reliably provide the same nutritional reward across species? The color of a fruit can honestly signal its nutritional content [15$18]$, or can be deceptive by mimicking a more nutritious fruit $[19,20]$. Although there are compelling reasons to expect that animal dispersers select for honest signals [18], this question has seldom been investigated. In the Atlantic rainforest of Brazil, darker fruit color was correlated with a more carbohydrate-rich pulp [18]. In the Mediterranean, however, darker colors were correlated with a lipid-rich reward [13, 17, 21]. These conflicting results suggest that, to the extent that color and nutritional content are correlated, the nature of those correlations may not be universal but particular to individual communities and/or plant clades.

Given confusion about the degree to which fruits fall into the classical bird and mammal syndromes, as well as our limited knowledge of how fruit colors relate to nutritional content, we sought to address fruit function and evolution at a different scale and from a different angle. Instead of asking whether fruits exhibit syndromes of traits according to their dispersers, we simply ask whether fruits within an individual clade exhibit distinct syndromes of any type. Furthermore, we ask how fruit trait diversity - in particular fruit color diversity - has evolved and whether we are able to identify any mechanisms that may underlie fruit color diversification. In this study, we use the flowering plant clade Viburnum as a model system to address these questions. Viburnum is a group of 163 species of mostly temperate forest shrubs and small trees of the Northern Hemisphere, although some species do occur in tropical regions of the IndoPacific as well as in cloud forests of Central and South America [22-25]. All Viburnum species produce fleshy, animal-dispersed drupe fruits and are largely birddispersed. Viburnum fruits are borne in clusters (infructescences) of $\sim 20-100$ fruits and display a wide variety of mature fruit colors, developmental patterns, and nutritional contents. Excellent knowledge of both the $\mathrm{Vi}$ burnum phylogeny based on chloroplast and nuclear
DNA sequences $[22,26,27]$ and fruit traits of many species $[24,26,28,29]$ make Viburnum ideal for a study of the evolution of fruit syndromes within putatively birddispersed species.

Mature fruiting displays can be decomposed into three main features in Viburnum: the color of mature fruits, the developmental pattern of those fruits, and the presence or absence of immature color stages. The majority of species display black or red fruits at maturity, but some species produce yellow, orange-red, or blue fruits (Fig. 1a). Developmental pattern refers to whether fruits mature synchronously or asynchronously, and this is closely related to whether fruits display immature fruit colors following the green stage (i.e., yellow and/or red). Sequentially developing fruits mature one at a time, such that mature fruits and contrasting immature fruits are present in the same infructescence (Fig. 1b). Synchronously developing fruits mature more or less at the same time in an infructescence, such that there is not a prolonged period during which there is a distinct color contrast between immature and mature fruits. Most synchronously developing Viburnum species develop directly from green to their mature color, though some do go through brief immature color phases [30, 31].

In addition to mature fruit color and developmental pattern, a fruit's morphological traits and nutritional content form important components of the fruit syndrome. All Viburnum species have drupe fruits with fleshy pulp surrounding a single seed that is encased in a hardened inner wall of the ovary, or endocarp [29]. The endocarp functions like a seed in that when a fruit is eaten, the whole endocarp passes through the gut of the animal and the pulp is removed. Endocarps in Viburnum range in shape from relatively flat to round, and they vary extensively in the degree to which they are grooved and therefore appear "wavy" in cross section (Fig. 1c) $[29,32]$. The nutritional content of the fruits of most Viburnum species is unknown, but the few that have been studied have lipid contents ranging from very low ( $\sim 2 \%$ dry weight, e.g., $V$. opulus) to very high ( $>40 \%$ dry weight, e.g., $V$. dentatum) [13, 33-37]. Of the species that have been studied, the vast majority are dispersed by birds although some dispersal by foxes, mustelids, and monkeys has been reported [38-42].

In this paper we address three questions about Viburnum fruit evolution in the context of the Viburnum phylogeny. First, we examine a set of 29 species in order to assess whether there are syndromes of traits in Viburnum fruits that have evolved in a correlated fashion, focusing on fruit color, fruit and endocarp size, and nutritional content. We then scale out to examine the evolution of selected fruit traits across a much larger set of Viburnum species. Specifically, we examine correlations in fruit color and endocarp shape across 115 
a) Fruit colors in Viburnum
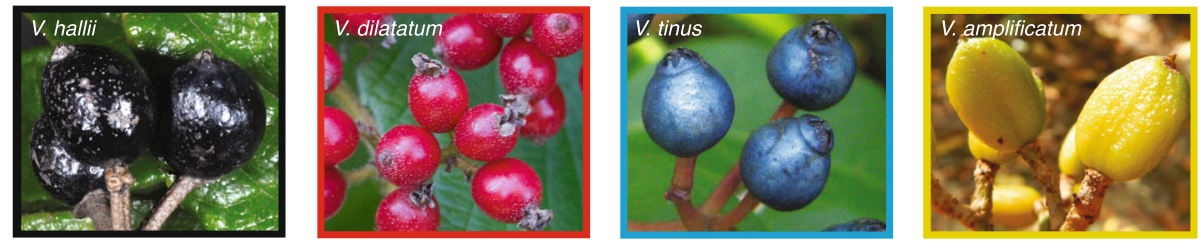

b) Developmental patterns
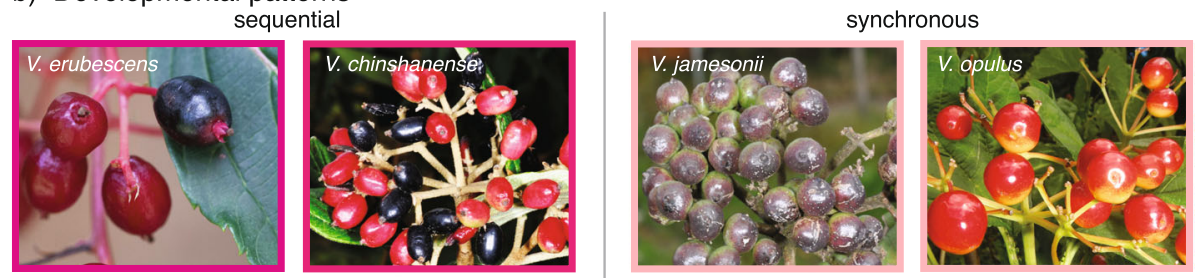

c) Endocarp shape
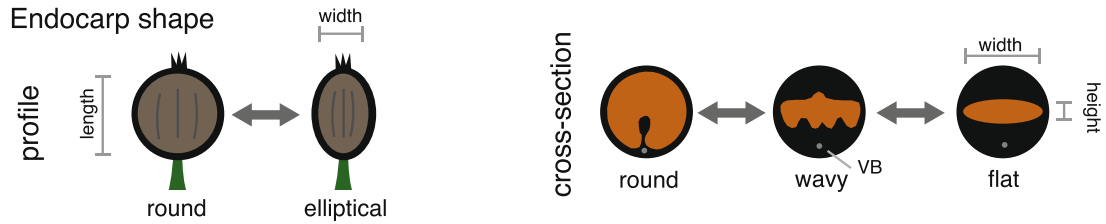

d) Independently evolved fruit color syndromes
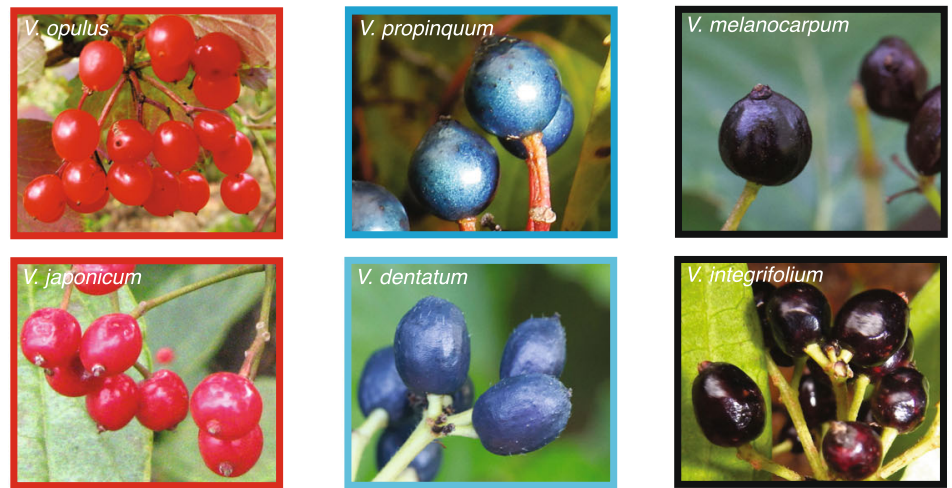

Fig. 1 Viburnum fruits exhibit a wide variety of fruit colors, developmental patterns, and endocarp shapes. a Viburnum displays four distinct colors at maturity: black, yellow, red, and blue. b Each species also exhibits one of two developmental patterns, either sequential (where immature fruits and mature fruits persist on the same infructescence, and the immature fruits provide a contrasting color to the mature fruits) or synchronous (where all fruits develop at the same time from green to their mature fruit color). $\mathbf{c}$ Endocarp shape varies in two dimensions: in profile, the endocarp may appear round or elliptical. In cross-section, the endocarp may appear round, flat, or wavy. Endocarp shape was measured according to the labels here (length, width, and height). d Viburnum fruit colors have evolved independently multiple times. Here, we illustrate these independent origins with example species from each origin. Black-sequential fruits only evolved once, but black-synchronous fruits evolved three times from red-fruited ancestors; shown here are two of those three origins

Viburnum species to assess their correspondence with our smaller subset of species. Finally, we infer ancestral fruit colors across all of Viburnum to trace the evolutionary assembly of fruit syndromes, specifically to test whether paedomorphic evolution could underlie fruit color diversification. Many Viburnum species exhibit a marked developmental color sequence, from green to yellow to red to black. In addition to species that exhibit this complete sequence, these colors also characterize the mature fruits of other species (e.g., $V$. amplificatum has yellow fruits, members of the Succotinus clade have red fruits, and members of the Oreinotinus clade have black fruits that for the most part lack intermediate yellow or red stages). Truncation of development in various ways - loss of intermediate red and yellow stages, or loss of the final black stage, for example could underlie transitions from a sequentially developing fruit to a wide variety of mature fruit colors. 
We seek to test whether paedomorphic evolution could underlie trait diversification in Viburnum, and possibly in other clades as well.

\section{Methods}

\section{Fruit traits}

We collected mature fruits from 29 Viburnum species, spanning all major clades and mature fruit color categories (accession numbers in Additional file 1: Table S1). For each species, we sampled fruits from a single individual (except for $V$. cylindricum, where multiple individuals were available and were needed to provide sufficient fruit material). Fruits were obtained from plants in the Arnold Arboretum (Jamaica Plain, Massachusetts, US), Kew Gardens (Richmond, UK), the Cambridge University Botanic Garden (Cambridge, UK), the Berkeley Botanical Garden (Oakridge, California, US), wild collections in Chiapas and Oaxaca, Mexico, and plantings in New Haven, CT. We measured reflectance and morphological traits (fruit and endocarp dimensions) for 20 fruits per species whenever possible, and separated pulp from endocarps for as many fruits as needed to conduct nutritional analyses (Additional file 1: Table S1).

\section{Reflectance}

In most cases, reflectance was measured on the day of sampling. If measuring reflectance was not possible on the day of collection, we kept the fruits chilled and in air-tight containers to prevent drying until reflectance could be measured. Reflectance spectra of 20 fruits per species (when possible; Additional file 1: Table S1) were measured with an OceanOptics USB2000 spectrometer with deuterium and halogen lamps and a Spectralon white reflectance standard (Ocean Optics, Dunedin, FL). Using the R package pavo [43], we smoothed the reflectance curve to $5 \mathrm{~nm}$ bands, set negative reflectance values to 0 , and smoothed background reflectance artifacts. After this processing, we averaged the reflectance measurements of all of the fruits measured per species to generate a mean reflectance spectrum per species. We then modeled each species in bird visual space using the UV-sensitive bird model in the $\mathrm{R}$ package pavo [43]. This model estimates the stimulation of UV-, short(blue), medium- (green), and long-wave (red) sensitive cones based on the reflectance spectrum. Using these models of fruit color, we estimated the volume overlap in tetrahedral color space of each pair of color categories.

\section{Morphology}

For each species, we measured fruit length, width, and height for 20 fruits per species (when possible;
Additional file 1: Table S1) using Mitutoyo Absolute Digimatic calipers. Length was measured from the base of the fruit to remnants of the calyx (Fig. 1c). Width and height were established based on the dorso-ventral axis of the endocarp (Fig. 1c). In Viburnum, the presence of a vascular bundle (centered on the ventral side and running from the bottom to the top of the ovary/fruit) provides a landmark for the measurement of the width and height (the dorso-ventral axis) of the fruit and the endocarp (Fig. 1c). In cross-section, "flat" endocarps, as we define them, are wide but not very high, whereas "round" endocarps are about as wide as they are high. We manually removed the pulp from 20 fruits, soaked them in water for $48 \mathrm{~h}$ and shook them for $5 \mathrm{~min}$ to remove any remaining pulp. These endocarps were then dried at room temperature and the length, width, and height were measured. We estimated the volume of both the fruit and the endocarp as an ellipsoid, and the volume of the pulp as the volume of the fruit not taken up by endocarp.

\section{Nutritional content}

Fruits were kept chilled at $4{ }^{\circ} \mathrm{C}$ until nutritional content could be analyzed; this was completed within 1 week of fruit collection. We separated the pulp from the endocarp, which is of no nutritional value to the disperser, to generate sufficient material for three measurements per species where possible. Overall, we dissected $>2300$ fruits with an average of 81 per species (ranging from 7 fruits for $V$. bracteatum to $>450$ fruits for $V$. propinquum). We quantified moisture content, ash, lipids, and protein, following the Association of Official Analytical Chemists (AOAC) methods [44]. For moisture and ash content, we dried $\sim 1 \mathrm{~g}$ of fresh fruit pulp at $110^{\circ} \mathrm{C}$ for $24 \mathrm{~h}$; the moisture content is the weight (water) lost after drying. We then combusted the dried sample at $550^{\circ}$ for $6 \mathrm{~h}$; the weight of the remaining material was the ash content. To quantify protein content, we employed the Kjeldahl method using the Kjeltec System 1002 (Tecator, Höganäs, Sweden) and estimated the protein content as $6.25 \times \mathrm{N}$. The lipid content was determined using a simple, rapid solvent extraction method adapted for plant tissues and enabling quantification on a relatively small mass of material [45]. We weighed $\sim 0.5-1.0 \mathrm{~g}$ of fruit pulp and homogenized this in a blender for $90 \mathrm{~s}$ with 20 $\mathrm{mL}$ of a 2:1 ratio of chloroform:methanol. After extraction, the sample was filtered and combined with $8 \mathrm{~mL}$ of $\mathrm{NaCl}$. This prevents emulsion formation and promotes clear separation of the chloroform layer (containing lipids) from the methanol layer. After separation, we dried $6 \mathrm{~mL}$ ( $4 \mathrm{~mL}$ for several samples) of the lipidcontaining chloroform layer at $\sim 80^{\circ} \mathrm{C}$ and weighed the resulting mass of lipids. Carbohydrates were taken as the remainder after lipids, protein, and ash were accounted 
for. We report here the mass of lipids, protein, ash, and carbohydrates based on the fresh pulp because dispersers consume fresh pulp rather than dried pulp; however, we also report dry mass values to provide comparability with related studies.

\section{Phylogeny}

For all Viburnum-wide trait evolution analyses, we used the phylogeny presented in Landis et al. [22]. In brief, this phylogeny jointly estimates the phylogeny using a combination of molecular sequence data (restriction-site associated DNA sequencing [RAD-seq] data for 118 species, plus chloroplast and nuclear DNA for 153 species), biogeographic information, biome affinity, and morphological trait data. Divergence times were estimated by including five fossil pollen grains in the analysis. Overall, this joint estimation of the phylogeny yielded a maximum clade credibility tree containing all of the currently recognized extant Viburnum species, for a total of 163 taxa plus five fossil taxa. This topology closely agrees with most recent estimations of the Viburnum phylogeny (e.g., [24, 26-28]), with one major exception. In previous phylogenetic reconstructions, $V$. clemensiae is placed as sister to the remainder of Viburnum. In Landis et al. [22], the position of $V$. clemensiae is equivocal. It is either placed as sister to the rest of $\mathrm{Vi}$ burnum or as sister to one of the two major subclades of Viburnum (containing Crenotinus + Valvatotinus + Pseudotinus + Urceolata). This difference has little impact on our understanding of fruit color evolution, with the possible exception of our estimation of the root state.

\section{Identification of syndromes}

To identify potential syndromes of fruit traits, we conducted a phylogenetic principal components analysis (PCA) using the R package phytools $[46,47]$ in order to identify whether different fruit color categories (as perceived by humans) occupied different regions of PC space. To incorporate evolutionary relatedness, we used the phylogeny described above [22] and assumed a Brownian motion correlation structure for each trait. We chose five non-color fruit traits to include in the PC analyses that were likely to influence selection on fruit traits by dispersers: lipid content, moisture content, pulp volume, endocarp flatness (width/height ratio), and fruit width. For nutritional content, we included lipid and moisture content. Since carbohydrates were calculated as the remainder after protein, ash, and lipids, it was inappropriate to include both carbohydrate and lipid content as these were highly correlated. Protein and ash both constituted $<10 \%$ of fruit nutritional content in nearly all species, and thus are unlikely to be an important factor in selection on fruit traits. For morphology, we chose endocarp flatness, fruit width, and the volume of pulp. The primary feature of endocarps in Viburnum is how flat versus round they are in cross-section, which we characterized by including the flatness dimension in our analyses. Fruit dimension variables were all highly correlated with one another, so we chose to include one variable (width) because that dimension likely determines whether the fruit can fit down a bird's throat [48]. Finally, the volume of pulp (the ratio of endocarp volume to fruit volume) is crucial because that volume determines the nutritional content of the fruit. We performed linear regressions of phylogenetic independent contrasts [49] as implemented in the $\mathrm{R}$ package ape [50], accounting for multiple comparisons using a Bonferroni correction. All variables were centered and scaled prior to analysis.

In addition to assessing trait syndromes in a subset of species for which we could gather a wide range of data, we also tested for correlated evolution of endocarp shape and mature fruit color across 115 species of Viburnum. Endocarp shape data from this broader sample of Viburnum were obtained from Clement et al. [32], and includes measurements for endocarp length, width, and height measured the same way as we measured our smaller subset of species. Endocarps for these species came from dried herbarium specimens with 1-3 samples per species. To assess the impact of fruit color category on the log of endocarp shape (specifically, flatness or the width to height ratio), we performed an analysis of variance (ANOVA) in the R package phytools and corrected for phylogeny by representing phylogenetic relatedness with a variance-covariance matrix of the dependent variable (endocarp shape). We additionally ran a nonparametric Kruskal-Wallis test in order to test for unequal sample sizes in endocarp shape across fruit color categories.

\section{Viburnum-wide color classification}

Information on mature Viburnum fruit colors and developmental patterns was based on our own field studies in all major centers of Viburnum diversity, observations in arboreta and botanical gardens, and published sources [30, 31, 51-56]. Even in a well-studied clade like Viburnum, there can be considerable disagreement as to the trait states for some species. The descriptions of fruits in floras and monographs usually rely on herbarium collections, which typically note the color of the fruits at the time of collection and may or may not indicate whether that fruit is mature. As a result, there can be inconsistencies between published accounts and field observations. For example, many species of Solenotinus are described as red-fruited in the Flora of China, but our own detailed observations of some species (e.g., V. subalpinum) demonstrate that they turn black shortly before 
dispersal or falling off the plant. We present here the results based on our field-based observations.

Above, we identified three relevant traits of mature fruits: color, developmental pattern, and presence or absence of immature color stages. Viburnum fruits that develop synchronously generally do not express immature fruit colors, or, if they do, those phases are quite limited. Thus, these two traits are redundant in this case. The fruits of all sequentially developing species are black at maturity, but there are also blackfruited species that mature synchronously (e.g., in the Porphyrotinus clade, $V$. acerifolium, $V$. melanocarpum, $V$. integrifolium). All blue- and red-fruited species also mature synchronously with the possible exception of $V$. clemensiae; few fruits are known from this species but they appear to mature to red following a noticeable yellow phase. The developmental pattern of the sole yellow-fruited species, $V$. amplificatum of Borneo, is poorly known, but for the purposes of this study we have classified it as sequential. Thus, while there are many possible combinations of these three traits (color, developmental pattern, and immature color stages), in Viburnum we observe only four major fruit color categories: black-sequential (which we have colored purple in all figures), black-synchronous (colored black), red-synchronous (referred to as and colored red), and blue-synchronous (referred to as and colored blue).

\section{Transition rate analyses}

We estimated the number of transitions as well as the rates of transition between the four major fruit color categories (black-synchronous, black-sequential, red, and blue) using stochastic character mapping [57], as implemented in the R package phytools [46]. We simulated 1000 character histories from which we calculated the average number of transitions between states, as well as the rates of transition between each color category.

\section{Ancestral state reconstruction}

In order to test the paedomorphy hypothesis, we inferred ancestral fruit color category using a phylogenetic tree for Viburnum [22]. We first implemented a paedomorphy model in maximum likelihood. We developed a transition matrix between each fruit color category that is congruent with the paedomorphy hypothesis (Additional file 1: Tables S2, S3) and then compared this model to the best of three other models of evolution (equal rates, symmetric, and all-rates different). Paedomorphic evolution could occur by truncation of the final color stage (e.g., a black-sequential fruit could lose the final black stage and thereby evolve red, or lose black and red to evolve yellow). Alternatively, intermediate stages could be truncated (e.g., a black-sequential fruit could lose the intermediate red stage and thereby evolve a black-synchronous fruit). Thus, we allow direct transitions from black-sequential to black-synchronous, red, and yellow. However, black-sequential fruits cannot transition directly to blue fruits, which are synchronous and produce their blue color via an alternative mechanism (structural color produced by lipid droplets embedded in the cell wall) $[58,59]$ and are most likely derived from ancestral black-synchronous fruits. We disallowed all transitions that did not involve a paedomorphic change, although we note that the transition matrix is symmetrical (such that if black-sequential can evolve into red, red can also evolve into black-sequential).

We implemented this model in both maximum likelihood [46] and parsimony (in Mesquite v. 3.3). In maximum likelihood, we defined a transition matrix according to the allowable transitions described above (Additional file 1: Table S2). For parsimony, we used a "step matrix" where the cost of a transition was counted as the sum of changes in fruit color, development pattern, or the addition of a structural blue color that occurred (Additional file 1: Table S3; [58, 59]). For example, the transition from black-sequential to blue fruits included a loss of intermediate color stages, the evolution of synchronicity, and the addition of a blue structural color (for a total cost of three). Likewise, the transition from red to black synchronous includes the addition of a black stage and the loss of a red stage but no change in synchronicity because both fruit types are already synchronous (for a total cost of two).

We then tested our maximum likelihood model against the most commonly used models (equal rates, symmetric, and all-rates-different) and selected the model with the lowest corrected Akaike information criterion (AICc). We compared the resulting paedomorphy model to that best model.

All data and analytical code are publicly available at Data Dryad: https://doi.org/10.5061/dryad.h44j0zpft.

\section{Results}

Color, nutrition, and morphology

Modeling of fruit color reflectance in UV-sensitive bird visual space yielded differentiation between red-fruited species (which occupied a distinct region of visual space) and the remainder (Additional file 1: Figure S1). A gradient occurs between black-fruited species (of both developmental patterns) and blue-fruited species, with the most extreme blue-fruited species being $V$. davidii. Short-wave cone stimulation (in the blue-region of the visible spectrum) provides the strongest differentiation between fruit color categories: red-fruited species have the lowest short-wave stimulation, followed by the black-fruited species of both developmental patterns, and finally blue-fruited species have the highest stimulation (Fig. 2). These color categories largely do not overlap in tetrahedral visual space: the only color categories with overlap $>0$ are the two black-fruited color categories (Additional file: Figure 
S2). As a consequence, although there is a gradient between black and blue fruit colors, these categories are distinct when modeled in bird visual space.

Nutritionally, Viburnum fruits varied dramatically along an axis from high moisture and carbohydrates to high lipids and low moisture and carbohydrates. Moisture and carbohydrates ranged from 48 to $90 \%$ and 8-36\% (34$93 \%$ dry mass), respectively (Fig. 2). Lipids constitute $0.2-$ $22.8 \%$ (1.6-58\% dry mass) of fruit pulp across species (Fig. 2). Protein content was low across all Viburnum species measured, ranging from $0.5-3.5 \%$ (1-9\% dry mass); ash was similarly low, $0.3-4.4 \%$ (2-12\% dry mass). Fruit length varied by a factor of $>3$ across species, from a minimum of $3.5 \mathrm{~mm}$ ( $V$. propinquum) to a maximum of $11 \mathrm{~mm}$ in length (V. prunifolium; Fig. 2). Pulp volume of the fruit varied from less than half (46\%) to nearly all (92\%) of the fruit (Fig. 2). Endocarp shape also varied enormously, from species that were extremely flat with an endocarp three times wider than thick (e.g., $V$. opulus) to species that were essentially round in cross-section (e.g., V. tinus).

\section{Fruit syndromes}

Figure 3 shows a phylogenetic PCA based on five fruit traits. The first two PC axes explain $55.1 \%$ and $20.1 \%$ of the variance, respectively (Fig. 3). PC1 is positively correlated with having higher lipid content, a low pulp volume (i.e., endocarp filling much of the fruit), small fruit size, and low moisture content. PC2 is positively correlated with high lipid content, and negatively correlated with having a flattened endocarp. Fruits occur along an axis of watery fruits with low lipid content that tend to be red or black-sequential in color, to blue or black-synchronous fruits that are low in water, high in lipids, and have endocarps that occupy more of the volume for the fruit.

\section{Phylogenetic independent contrasts (PICs)}

Pairwise regressions between PIC values of short-wave reflectance and the five fruit trait variables (lipid content, moisture content, pulp volume, endocarp flatness, and fruit width) indicate that color, especially a blue color, is correlated with higher lipid content (Fig. 4).

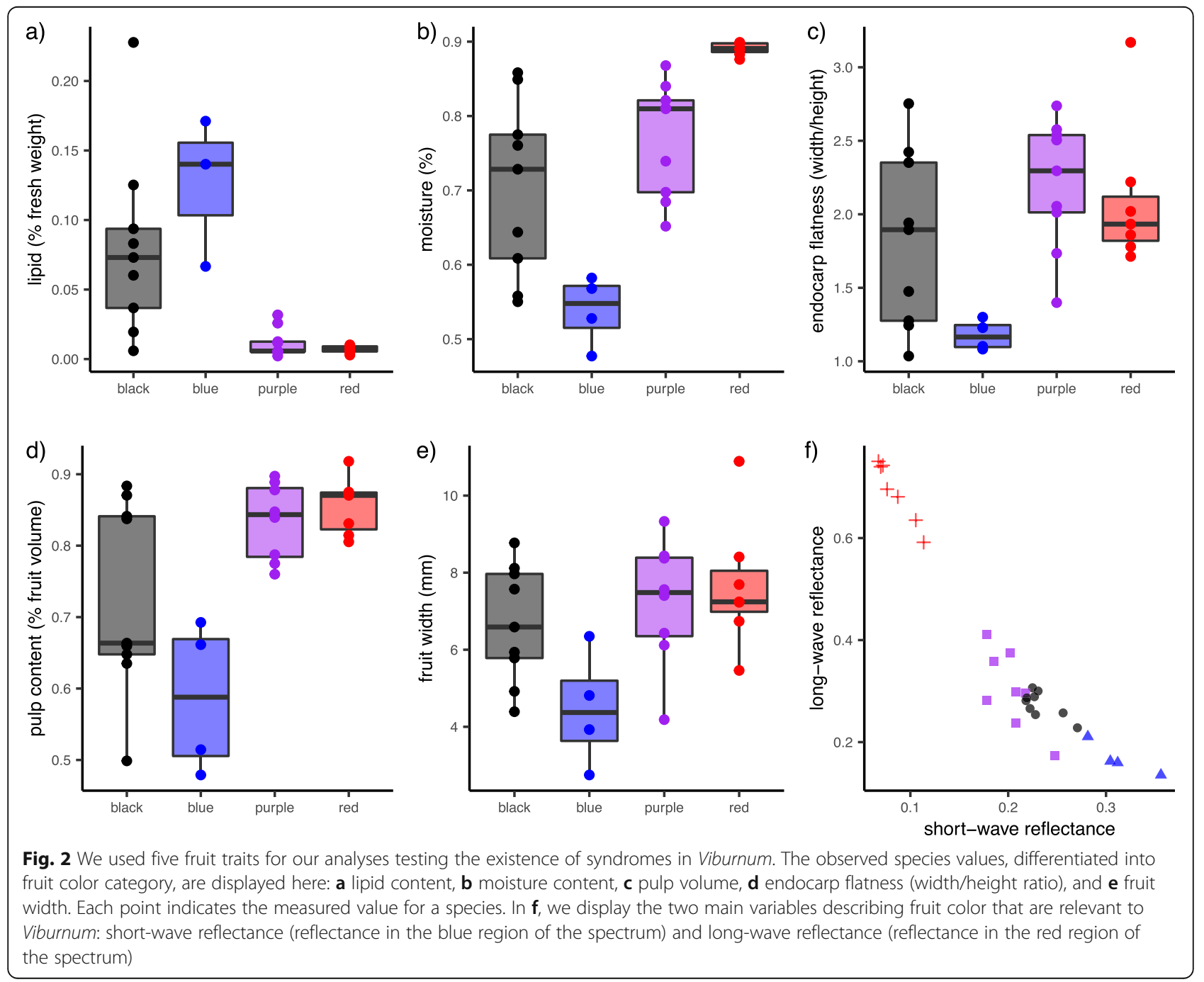




\section{Endocarp shape and fruit color correlations across Viburnum}

Across 115 species of Viburnum, there was not a statistically significant difference in the log of endocarp shape across fruit color categories $(\mathrm{F}=1.66, p=0.18$; Fig. 5), even when we excluded the outlier $V$. clemensiae $(\mathrm{F}=$ $1.74, p=0.16$ ). However, our fruit color categories have non-equal variance (the blue-fruited color category has lower variance than any of the others; Brown-Forsythe test, $\mathrm{F}=3.0, p=0.03$ ) as well as unequal sample sizes. As a consequence, we additionally used a non-parametric test, the Kruskal-Wallis test, which was significant (chisquared $=37.0, p<0.001$ ), although this test does not incorporate phylogenetic relatedness. Overall, we find mixed evidence of a difference in endocarp shape across fruit color categories. Both black fruit types (black-sequential and black-synchronous) have variable endocarp cross-sections from flat to relatively round; blacksequential fruits, in particular, have explored nearly the entire endocarp shape space. We found little evidence of significant differences in endocarp shape viewed in the longitudinal (length) dimension across fruit color categories, with the exception that black-sequential fruits include a few species with more elliptical endocarps than in other color categories.

\section{Ancestral state reconstructions}

Stochastic character mapping estimated an average of ten transitions in fruit color across the Viburnum tree (Fig. 6; Fig. 7). One transition from black-sequential to red was inferred along the branch leading to $V$. clemensiae. Two transitions from black-synchronous to red were also identified, in 1) the Opulus clade, and 2) the Succotinus+Lobata clade. Three transitions from red to black-synchronous were also inferred, along the branches leading to 1) V. melanocarpum, 2) V. integrifolium, and 3) V. acerifolium. Two transitions from blacksynchronous to blue were inferred. One of these occurred along the branch leading to the Tinus clade. The second occurred along the branch leading to the $V$. dentatum complex. A single shift from black-sequential to yellow was inferred along the branch leading to $V$. amplificatum. Finally, a shift from black-sequential to black-synchronous occurred early in Nectarotinus evolution, but the branch on which this transition occurred is uncertain. Due to the uncertain location of this transition, in some reconstructions multiple transitions from black-sequential to black-synchronous are inferred in order to explain the present-day distribution of traits. Seven of the nine transitions with relatively certain locations occurred in the large Nectarotinus clade; the only

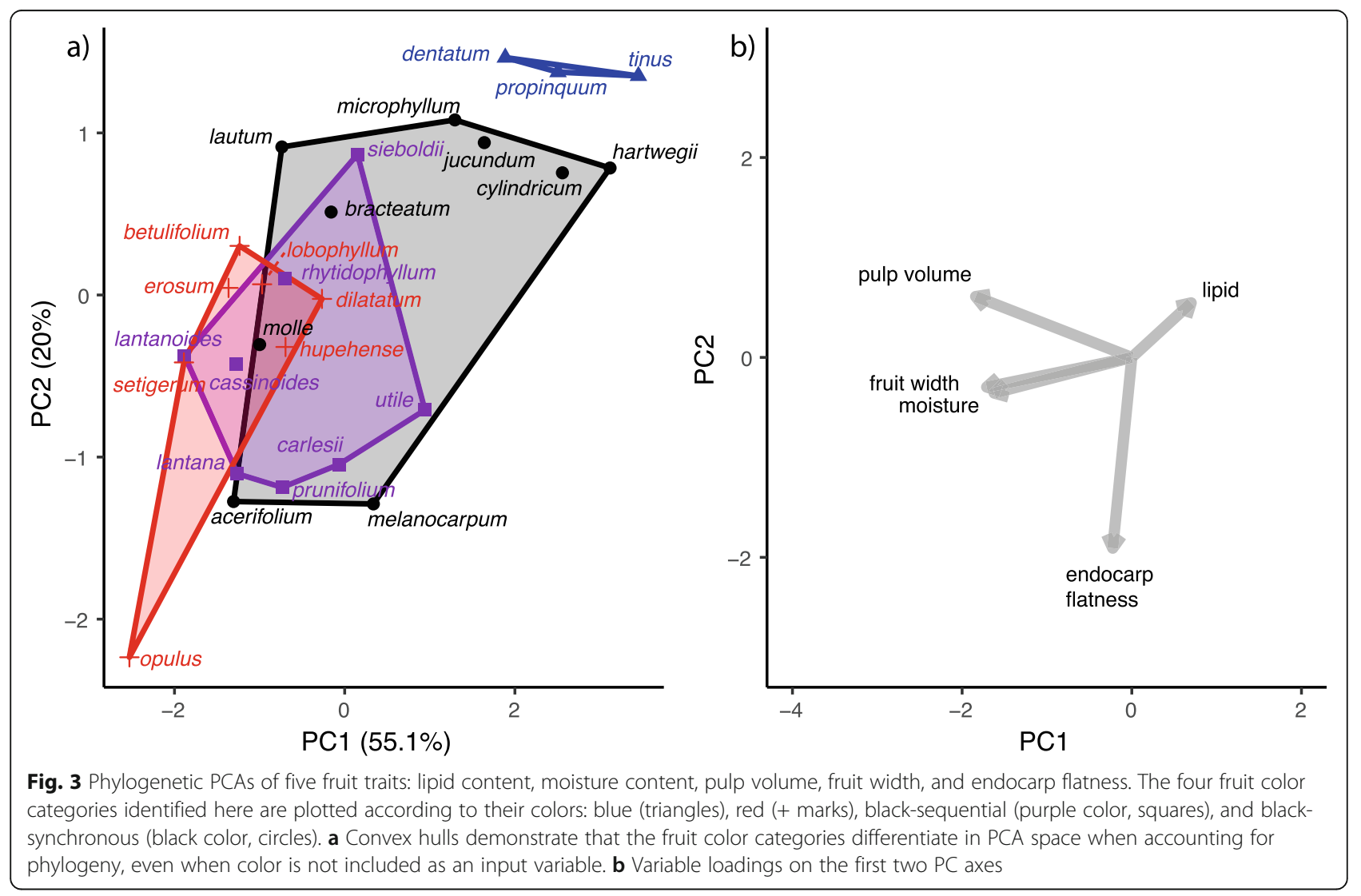




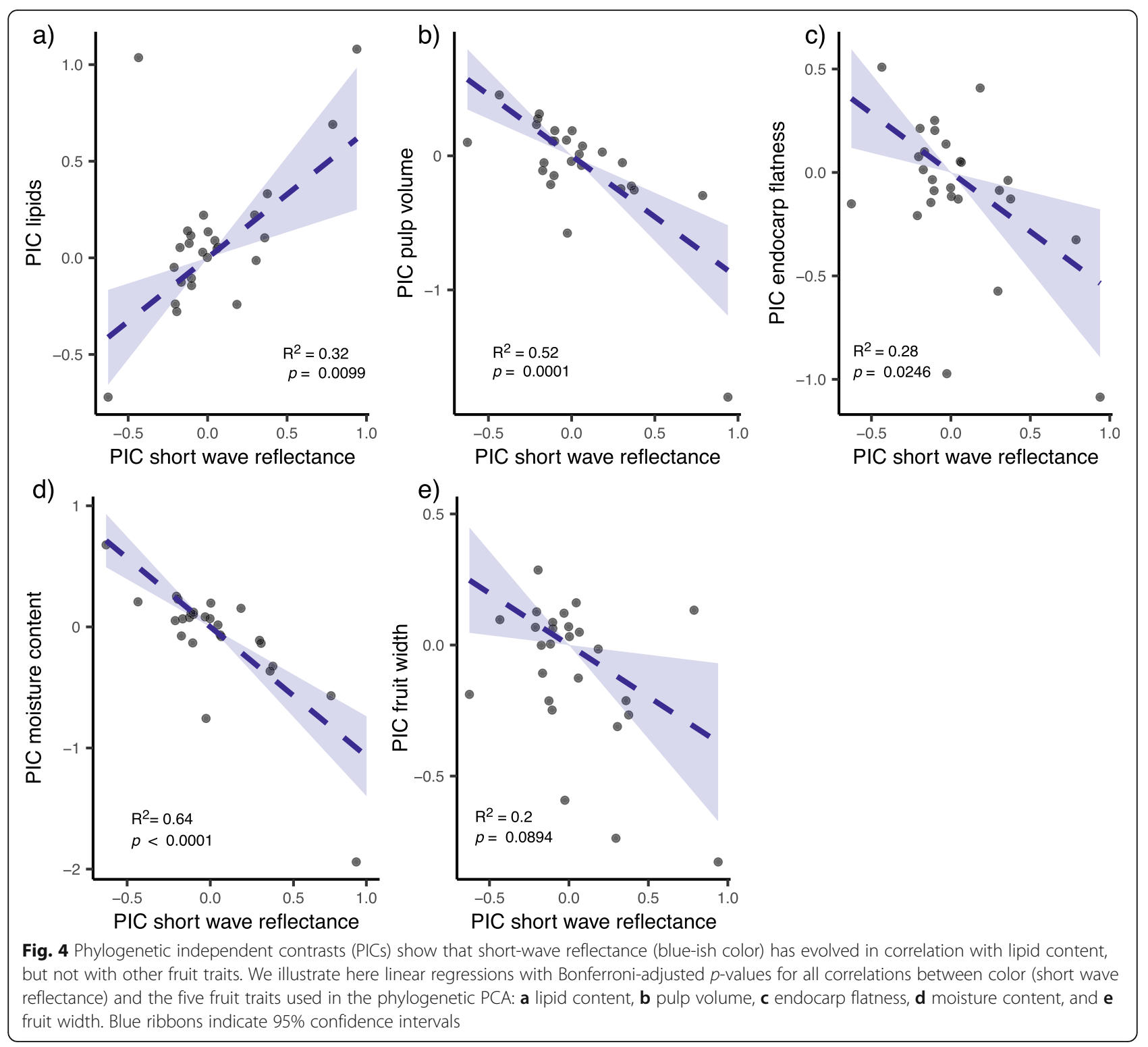

exceptions are the transitions to red in $V$. clemensiae and from black-sequential to yellow in V. amplificatum.

Our maximum likelihood models favored the ancestor of Viburnum as most likely exhibiting a black-sequential (indicated in purple in Fig. 6) fruit color, but we note that this is equivocal. In contrast, our parsimony models favored a red-, black-synchronous, or black-sequential ancestor. This root state is thus ambiguous. As discussed further below, the condition in the ancestor of the Nectarotinus clade (Fig. 7) is critical in assessing the role of heterochrony in Viburnum fruit evolution, as most of the fruit color diversity (and hence most of the potential for paedomorphic evolution) occurs in this clade. We find that the ancestral state of Nectarotinus depends strongly on the model of character evolution. The best model of evolution under maximum likelihood was the equal rates model (where all transitions are allowed), and reconstructs Nectarotinus as most likely blacksynchronous, with red-synchronous as the second most likely state (black-sequential also has moderate support) (Fig. 6a). Under parsimony, the backbone of Nectarotinus is most likely red (when transitions are unconstrained; Fig. 6c). Under our paedomorphy model, maximum likelihood infers that the ancestor of Nectarotinus was almost certainly black-synchronous, while parsimony reconstructs that this ancestor was either blacksynchronous or red (Fig. 6b, d).

\section{Discussion}

We find strong support for the existence of fruit syndromes in Viburnum, with significant correlations between fruit color, morphology, and nutritional content 


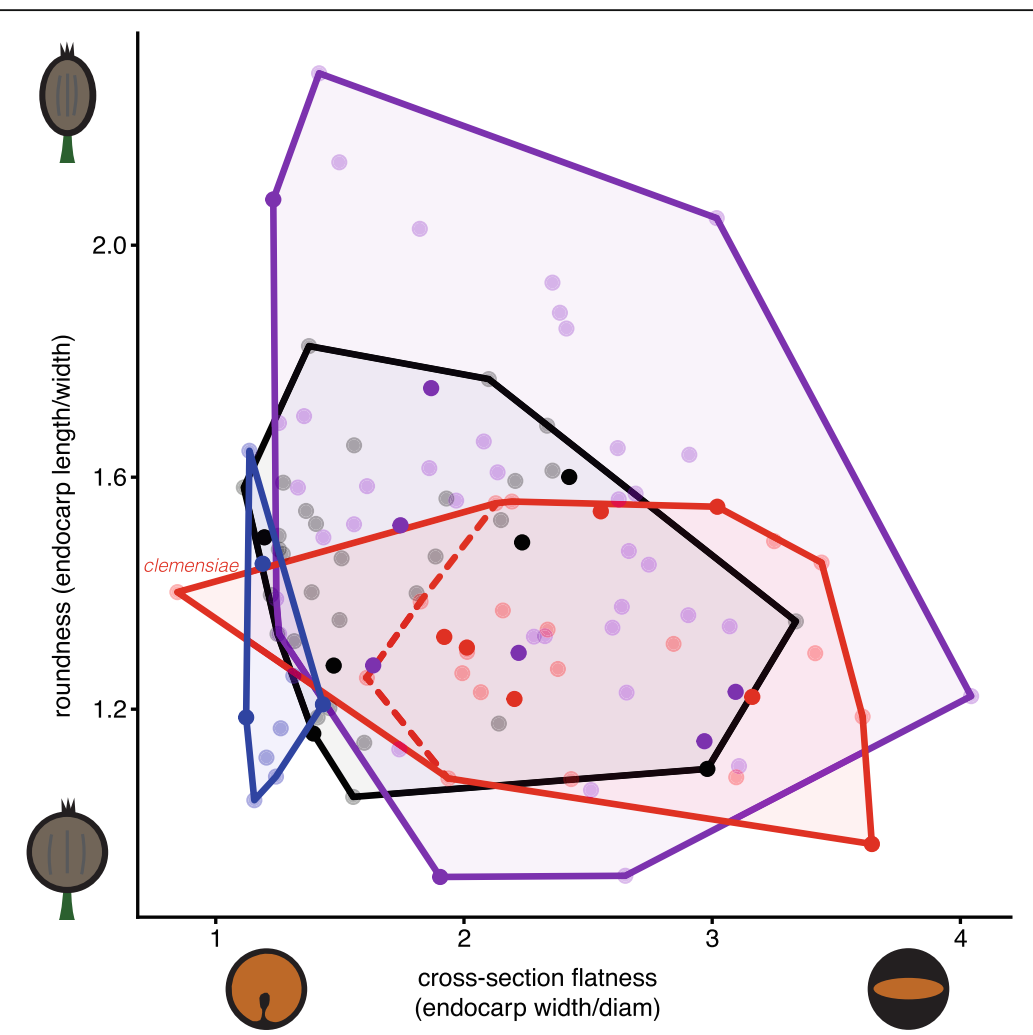

Fig. 5 Blue and red fruits display different endocarp shapes across a broad range of Viburnum species (115 species). On the x-axis, we plotted endocarp shape in cross-section, where species with small values have rounder cross-sections while species with high values have flatter crosssections. On the $y$-axis, we plotted endocarp shape in profile, where low values indicate round endocarps and high values indicate elliptical endocarps. Red-fruited species have flat endocarps, while blue-fruited species have rounder endocarps. The one exception is $V$. clemensiae, which is red but has a round endocarp (labeled to illustrate its position in endocarp shape space). The dashed red line shows the shape space for all red-fruited species excluding $V$. clemensiae. Opaque dots indicate species for which we generated new nutritional data in this paper

(summarized in Fig. 7). We identify two strong syndromes (in blue- and red-fruited species) as well as a weaker syndrome (black-sequential) and one fruit color category with high variability (black-synchronous). Blue fruits are high in lipids, with low moisture content and relatively small, round endocarps. Red fruits exhibit traits on the opposite end of the spectrum: they tend to have low lipid content but very high moisture, and are larger in size with a flatter endocarp. These two syndromes likely both evolved from black-synchronous ancestors (although black-sequential is also a possibility; see below). Species with black-synchronous fruits do not form a single clade and, not surprisingly, exhibit the highest variability. Some resemble red-fruited species, including $V$. acerifolium and $V$. melanocarpum. This makes sense as these species appear to have evolved quite recently from red-fruited ancestors. Other blacksynchronous species resemble their blue-fruited relatives in having high lipid content and large, round endocarps. Black-sequential fruits most resemble red fruits in having a relatively high moisture content and low lipid content. However, unlike red fruits, black-sequential fruits vary enormously in the shapes of their endocarps, from very flat (e.g., $V$. lentago) to round (e.g., V. sieboldii).

The differences between red and blue fruits are particularly striking. Blue fruits are lipid-rich with a low moisture content and have a large, round endocarp that takes up much of the fruit's volume, leaving only a small quantity of nutritious pulp. This syndrome evolved twice, once in the Tinus clade and once in Dentata. Relatives of $V$. dentatum in the Porphyrotinus clade (e.g., V. molle, V. bracteatum, and $V$. lautum) have high lipid content (7.3$12.5 \%$ [22-35\% dry mass] with the exception of $V$. jucundum with only $3.7 \%$ [ $9 \%$ dry mass]), which suggests that high lipid content evolved prior to the origination of blue fruit color in V. dentatum. Because blue fruits in Viburnum embed lipids in their cell walls to produce a structural color $[58,59]$, the evolution of lipid-rich pulp prior to the evolution of a blue fruit color suggests that the upregulation of lipid synthesis may have set the stage for the subsequent use of lipid droplets in the production of structural color. All species in the Tinus clade have blue fruits and likely have high lipid content, so in this case the order in which these traits evolved is unclear. 

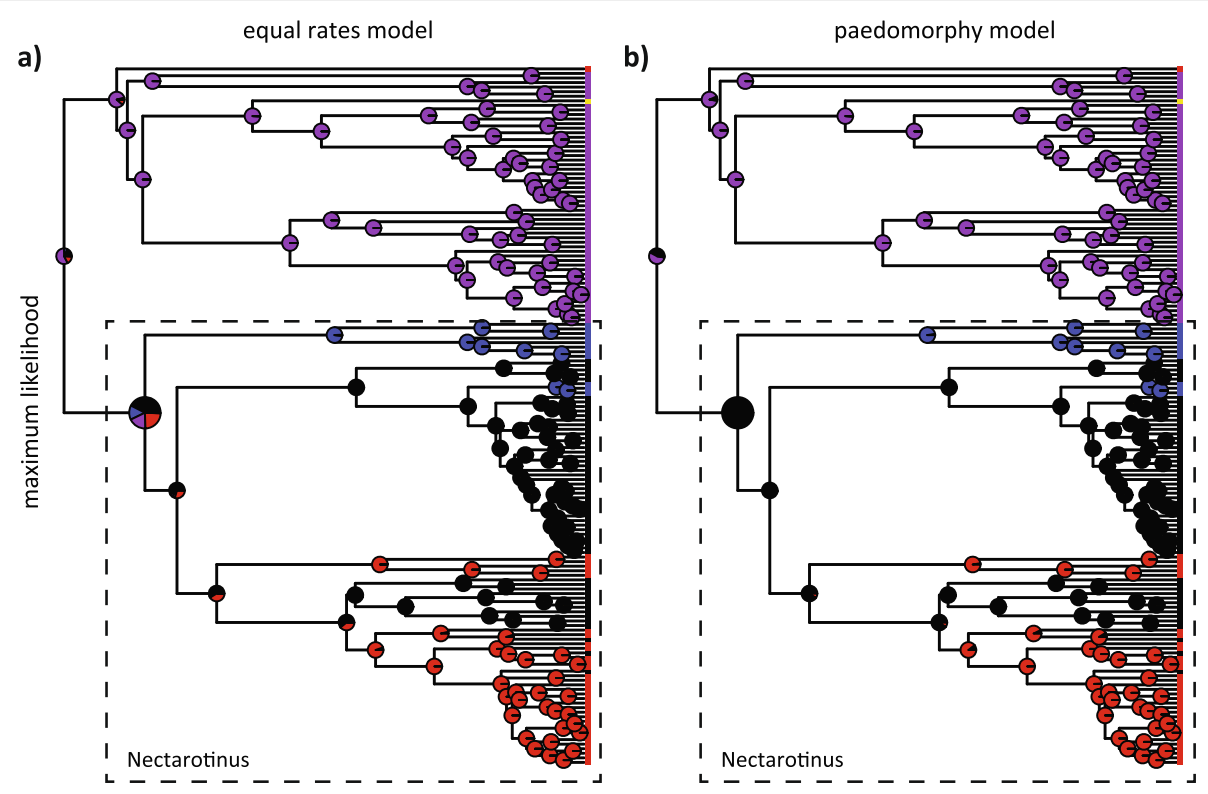

c)

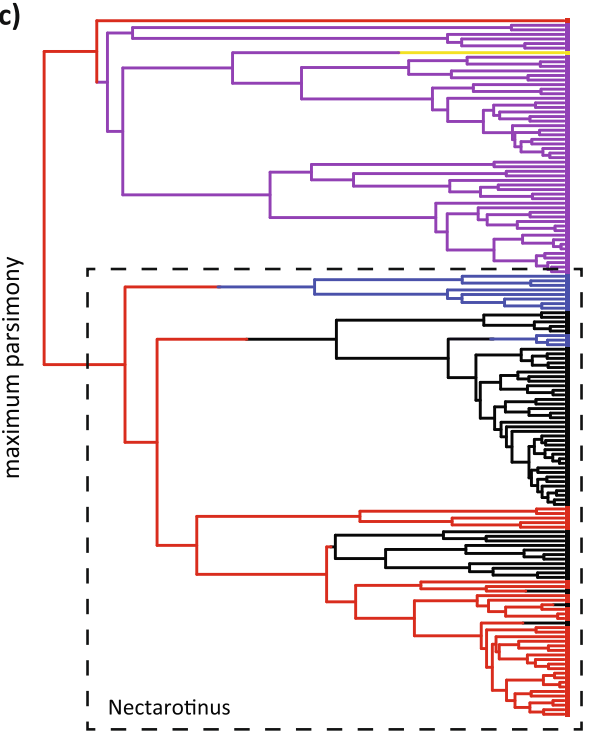

d)

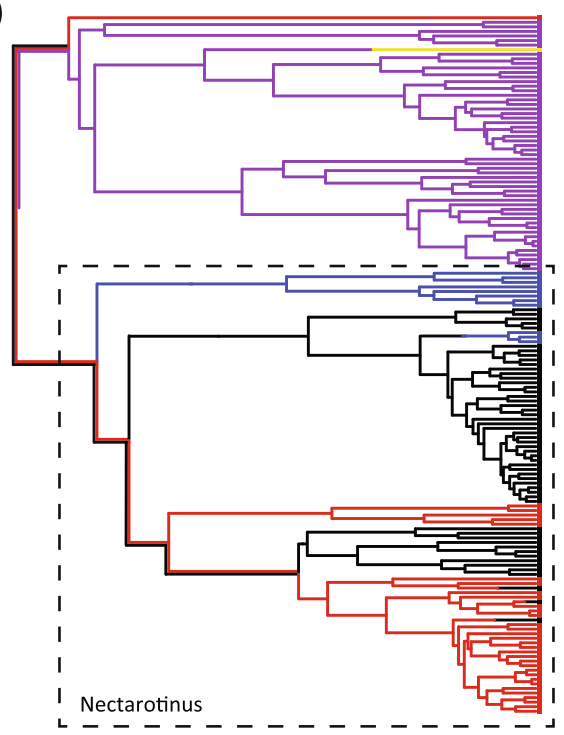

Fig. 6 Ancestral state reconstructions of Viburnum fruit color, using maximum likelihood and parsimony and two different models of character evolution (equal rates/costs and paedomorphy). a Maximum likelihood reconstructs the ancestral state of Nectarotinus as most likely black-synchronous or red under the equal rates model, and as black-synchronous under the paedomorphy model. b Parsimony reconstructs the ancestor of Nectarotinus as red according to the equal rates model, but as black-synchronous or red according to the paedomorphy model. None of these analyses strongly support a paedomorphy hypothesis in which the ancestor of Nectarotinus was black-sequential. The Nectarotinus clade is indicated by the dashed line, and the colors of branches, tip labels, and node reconstructions indicate the fruit color category of the species (purple = black-sequential, black= black-synchronous, red $=$ red-synchronous, blue $=$ blue-synchronous)

Across 115 species of Viburnum, mature fruit colors occupy distinct regions of endocarp shape space that correspond with the syndromes described here: blue fruits have rounder endocarps, red fruits have flattened endocarps, and both black fruit types (sequential and synchronous) span nearly the whole range of endocarp shapes. The only exception to this is the red-fruited $V$. clemensiae, which has a round endocarp more similar to blue-fruited species. The fruits of $V$. clemensiae are poorly known and only a handful have ever been collected, but analyzing their nutritional content would provide further insight into the evolution of fruit syndromes in Viburnum. Aside from V. clemensiae, red fruits are juicy, with high moisture content, low lipid content (and corresponding high carbohydrate content), and a flattened endocarp that takes up a small portion of the total volume of the fruit. This syndrome evolved twice, once in the Opulus clade and once in the 
Succotinus+Lobata clade. It is especially well developed in the Opulus clade, where the fruits have exceptionally flattened (nearly ungrooved) endocarps [32].

The selective pressures driving Viburnum fruit evolution are unknown, but may relate to disperser characteristics. For instance, migratory birds may consume lipid-rich fruits in order to meet their daily energy requirements, as lipid content is positively correlated with a fruit's energy density [3, $33,60,61]$. This energy-dense fruit comes with a high cost, however: the bird must carry the weight of the endocarp in its gut until defecation. In the Mediterranean, preferential consumption of lipid-rich fruits during winter by European robins (Erithacus rubecula) has been noted [62]. Similar patterns have been reported in eastern North America, where lipid-rich fruits (including $V$. dentatum) are consumed by migratory birds more frequently than are less lipid-rich species [33, 34, 63]. However, birds are rarely observed consuming only lipid-rich fruits, and instead they switch between complementary food sources where some food items play a major role in their diet and others a minor role [21, 64]. Red, juicy fruits appear to target a different feeding strategy and offer a low-quality reward (mostly water, a little sugar) at a low cost (a small endocarp). These two syndromes thus represent two distinct strategies: high value, high cost, combined with a highly distinctive color in the case of blue fruits, and low value, low cost, and a common color in the case of red fruits.

Dispersers do appear to choose fruits based on the relative ratio of reward and cost [65]. A large, round endocarp - a higher cost to a bird - may have been enabled in blue-fruited lineages in part because of the high value of the lipids, which are energy dense and relatively rare in fruits [66]. Because blue-fruited species offer a highquality reward, they are able to produce a higher cost and still be dispersed. Black-fruited species reflect a similar, though weaker, pattern. Species with larger, rounder endocarps - e.g., black-synchronous species such as $V$. hartwegii, $V$. jucundum, and $V$. lautum, as well as blacksequential species such as $V$. sieboldii - also tend to have elevated lipid levels. Black-sequential species with flatter endocarps (e.g., $V$. prunifolium, $V$. lantana) have very low lipid content, similar to lower quality red-fruits, which would likely be consumed only rarely if they did not offer a larger quantity of reward.

Broadly speaking, fruit colors in Viburnum - especially blue and red - appear to act as honest signals: blue color always occurs with higher-value, lipid-rich pulp, while red color is associated with larger quantities of water- and sugar-rich pulp. In addition to inferring something about the nutritional content of a Viburnum fruit based on its color, dispersers can also infer that a blue fruit will have a higher cost than a red fruit in terms of endocarp size relative to the quantity of pulp. The overall value of consuming any individual fruit depends on the quantity and value of the reward as well as on the size of the endocarp.

\section{Evolutionary origins of fruit color diversity}

To better understand the evolutionary origins of fruit color diversity in Viburnum, we conducted a series of ancestral state reconstructions meant to assess whether paedomorphic evolution can explain Viburnum fruit color diversity. The root ancestral state of Viburnum is equivocal, and was likely either black-sequential (as suggested by maximum likelihood) or red (as suggested by parsimony), although black-synchronous is also possible. Most of our models prefer a black-fruited ancestor, either sequentially or synchronously developing. Paedomorphic evolution, if true, would suggest that the ancestor to Viburnum likely experienced a series of color stages during development that were subsequently modified. However, the topology of the Viburnum tree makes it difficult to confidently infer the ancestral state, and without alternative lines of evidence we cannot say with any degree of certainty what fruit color category and developmental pattern this ancestor displayed. The sister group to Viburnum includes Sambucus (elderberries), which also produces fleshy fruits. Phylogenetic analyses suggest that black fruits are ancestral within Sambucus, and red fruits are derived [67]. This lends some support to the view that mature black fruits are ancestral in $\mathrm{Vi}$ burnum, but it does not help with the developmental pattern, as these have not been well documented in Sambucus.

The equivocal nature of our reconstructions is unsurprising, because Viburnum undergoes a bifurcation early in its evolution. One major branch exhibits almost entirely black-sequential fruit development, while the other exhibits a wide range of fruit colors. In one of these clades (including V. clemensiae, Valvatotinus, Crenotinus, Pseudotinus, and Urceolata) the fruits develop sequentially. Our reconstructions favor black-sequential as the ancestor of this clade, though red is also a possibility according to parsimony. As far as is known, all species except two retain this presumed ancestral condition. We note, however, that in spite of decades of research on $\mathrm{Vi}$ burnum there are species whose fruit development is still poorly known (e.g., the two Punctata species). There is also considerable variation in the realization of this fruit color category. In some species the red phase is very short and black fruits persist for many months (e.g., $V$. lentago), while in others the red phase is prolonged and the fruits turn black (and juicy) only shortly before dispersal (e.g., $V$. erubescens). The two species within this clade known to have substantially modified this developmental program are $V$. clemensiae and $V$. amplificatum. In both species, paedomorphic evolution is possible although would need to be further studied to be 


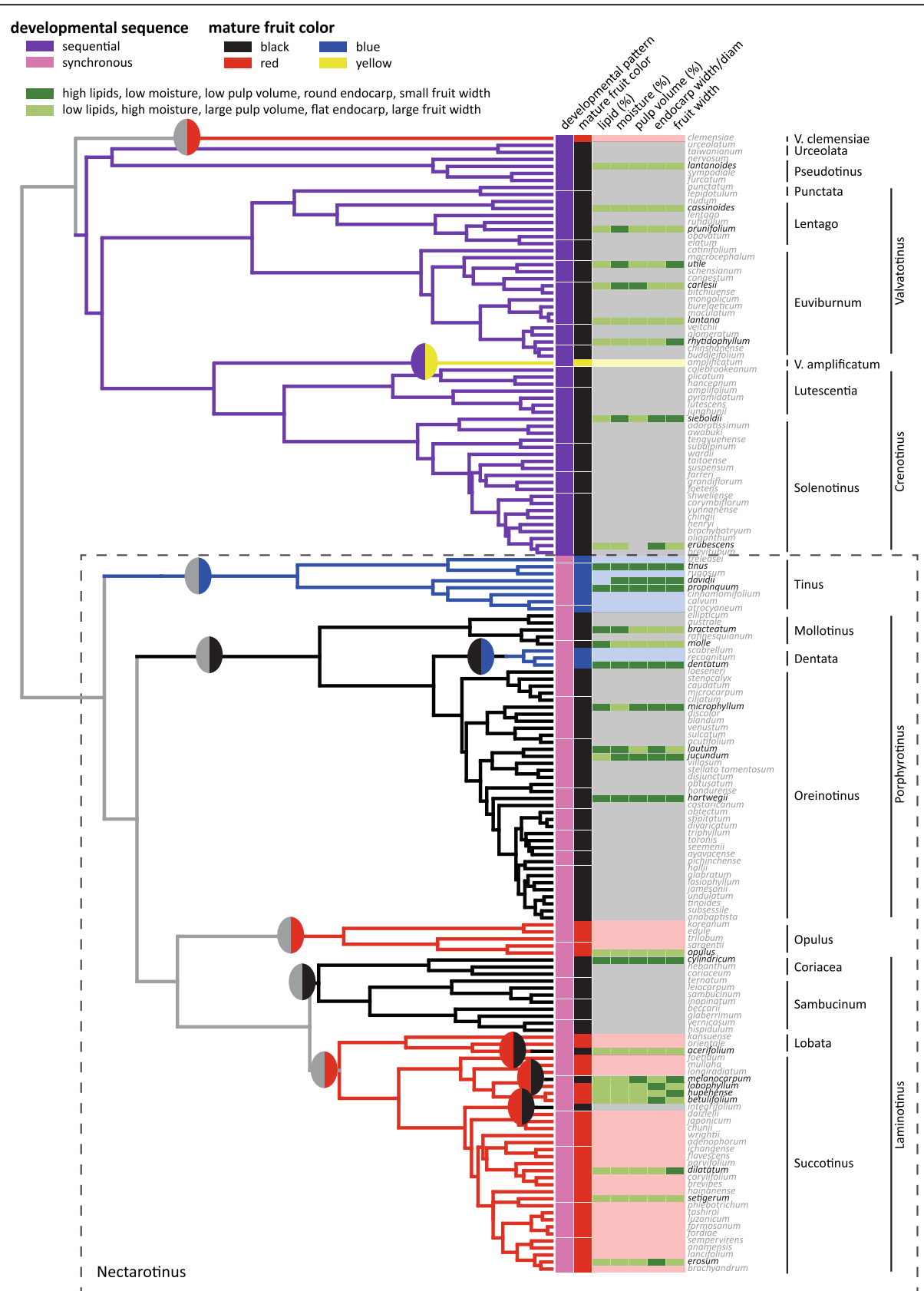

Fig. 7 Viburnum fruits have evolved syndromes of traits, multiple times. Blue-fruited species have high lipid content, low moisture, low pulp content, and a rounder endocarp. Red-fruited species have extremely high moisture content and pulp content, low lipids, and a flatter endocarp. Illustrated here are the main traits we examined in this analysis, classified as to whether they resemble the blue-fruited syndrome or the redfruited syndrome. We used the mean value of each trait as the threshold, and determined whether blue-fruited species had "high" or "low" values for that trait. Black-fruited species (both synchronously and sequentially developing) exhibit a range of traits, including some species with intermediate moisture levels that differ from those found in red-fruited or blue-fruited species. Gray branches indicate regions of the phylogeny where the ancestral state is especially equivocal

confirmed. V. clemensiae, to the best of our knowledge, has red fruits at maturity, which could have evolved from a loss of the final, mature black stage. V. amplificatum matures exceptionally large yellow fruits that could potentially be mammal-dispersed (perhaps by orangutans, which occupy the same forests). As with $V$. clemensiae, this condition could possibly have evolved by the loss of the final red and black stages.

In the other major clade (Nectarotinus), our models disagree as to the ancestral state. This is the clade within which fruit color diversification seems to have occurred at a higher rate, driven possibly by paedomorphic 
evolution or by some other process. Seven of the nine confidently inferred fruit color transitions occurred in Nectarotinus; only two transitions occurred in the other major clade. According to our models, the ancestor to Nectarotinus was most likely black-synchronous, but could have been red, black-sequential, or, less likely, even blue. The difficulty of confidently reconstructing ancestral states reflects the early bifurcation of the $\mathrm{Vi}$ burnum phylogeny, one with nearly all the same fruit color category (black-sequential) and one (Nectarotinus) with a wide variety of fruit color categories. This topology is not amenable to confident ancestral state reconstructions, and alternative lines of evidence would be needed to bear more strongly on this question. There is an alternative topology for the Viburnum phylogeny than the one we have used here; most phylogenetic analyses have placed $V$. clemensiae as sister to all remaining Viburnum, rather than as sister to one of the two major clades [22, 24]. However, this alternative topology does not alter the ancestral state reconstructions significantly. With $V$. clemensiae placed sister to the rest of Viburnum, we would have three lineages, each with a different fruit color category: one red-fruited, one blacksequential, and one possibly black-synchronous although equivocally so. Overall, we do not find strong support for the paedomorphy hypothesis, which would only be favored if this ancestor were confidently reconstructed as black-sequential.

The equivocal nature of these reconstructions suggests that perhaps the ancestor to Nectarotinus did not fall neatly into either of the two categories that we have used to describe extant black fruits, black-sequential and black-synchronous, and instead was a non-analog fruit type that exhibited both synchronous development and the immature color phases. Synchronous fruit development clearly evolved along the branch subtending Nectarotinus. However, immature color phases may not have been lost along the same branch, and evidence from extant species supports this possibility. We have broadly characterized synchronously fruiting species as lacking immature color phases, but this is not strictly correct. Some extant species in Nectarotinus do exhibit immature red colors. For instance, $V$. ellipticum has a clear red phase but the fruits mature relatively synchronously [56]. Viburnum tinus and V. cylindricum sometimes exhibit red phases, though to a much lesser extent and also with considerable variation among individuals. If the ancestor to Nectarotinus had a more pronounced red phase than we find in synchronous species today, the immature red phase in this non-analog ancestral fruit type would have been lost or greatly reduced multiple times (in Tinus, Porphyrotinus, and Coriacea + Sambucina). And, if enough of a red phase persisted in the ancestor of Nectarotinus, this could have provided the basis for paedomorphic evolution of red fruits in the Opulus and Succotinus+Lobata clades. The Opulus and Succotinus clades display additional attributes that are consistent with their fruits having been juvenilized. For instance, they tend to hang on the plant for long periods of time after maturing [68], and are relatively unpalatable $[69,70]$ - both traits that are characteristic of a juvenile fruit that needs to remain attached and uneaten.

If the ancestor to Nectarotinus likely did not have a fully sequentially developing fruit, can paedomorphic evolution nonetheless explain the variety of fruit syndromes within Nectarotinus? One possibility is that the shift to synchronicity along the Nectarotinus branch enabled the subsequent diversification of $\mathrm{Vi}$ burnum fruit colors via paedomorphic evolution. For a sequentially developing fruit to undergo paedomorphy, selection for fruit colors would have to be strong and consistent over much of the maturation period, which often lasts for several months in Viburnum. Synchronously developing Viburnum fruits, on the other hand, tend to fruit for shorter periods of time during the late summer and fall. For these fruits to evolve paedomorphically, migratory birds would need to arrive only a short period of time before fruits were fully mature. At that point, a mismatch in the timing of maturation and bird migration of a few days or weeks could drive birds to consume immature fruits and consequently to select for fruit maturation at an earlier color stage. If the ancestor to Nectarotinus were a non-analog fruit type that developed synchronously and over a short period of time, but retained an immature red phase, even small mismatches in timing could have promoted paedomorphic evolution.

Regardless of whether such paedomorphic evolution drove fruit color diversification, synchronicity may represent a fundamental shift in strategy away from targeting residential birds and towards targeting migratory and/or flocking birds. For the most part, sequentially developing species fruit over weeks or even months (cf. the temporally bicolored fruits described by [71-73]) and potentially target summer resident birds as their primary dispersers. Birds are able to select mature fruits out of mixed displays, and may use information about the relative ratio of immature to mature fruits to choose which fruits to consume [74]. Sequentially developing species advertise their future ripe fruit, in addition to clearly identifying currently ripe fruit, through the temporal contrast between immature fruit colors and mature fruit colors.

In contrast to sequentially developing species, synchronously developing species may target flocking and/ or migratory birds. In the synchronously fruiting $V$. dentatum, larger crop sizes are associated with higher rates 
of removal by flocking bird species [75], although fruits are removed more slowly when individuals occur in large clumps [76]. These different strategies - should they hold up to future research - may also explain the great diversity of fruit colors in the Nectarotinus clade. The need to maintain multiple color stages may limit the rate of evolution in sequentially developing species, and this may extend beyond just the mature color of the fruit to nutritional traits. Sequentially developing species retain similar nutritional content (relatively low lipids, high carbohydrates, and intermediate moisture), though they do vary in their endocarp shapes. As a consequence, sequentially developing species, by and large, have not deviated significantly from their presumed ancestral fruit. At this point it is impossible to say whether it is purely a result of phylogenetic accident that this large clade does not appear to have explored trait space very much, or whether there are constraints that make deviation from this fruit unsuccessful. But we find it intriguing that sequentially developing fruits exhibit relatively little variance in their traits, while synchronously developing fruits exhibit a much greater diversity in fruit color, nutrition, and morphology.

Synchronously developing species are not constrained by the need to display immature and mature colors simultaneously and thus are free to evolve in response to other selective pressures. For instance, they may evolve distinctive colors in order to more effectively compete for dispersers, or mimic higher quality fruits $[20,77]$. We see this possibility in the blue-fruited syndrome. Sequentially developing fruits may reduce competition for dispersers by spreading their fruiting out over a longer period of time [78], while mast fruiting in synchronously developing fruits may be advantageous in relation to attracting migratory and/or flocking birds that consume large quantities of fruit at once [33, 34, 63]. At the same time, synchronicity might also promote the evolution of specialized fruit colors and nutritional content.

Our ancestral state reconstructions and transition rate analyses support the notion that rates of trait evolution have been higher in Nectarotinus. When we estimate transition rates between each fruit color, we find that the highest transition rates are between red and blacksynchronous (Additional file 1: Table S4). The high rate of red to black-synchronous transitions is driven by the three independent origins of black-synchronous fruits from red-fruited ancestors, all of which happened relatively recently ( $V$. acerifolium in the Lobata clade, and $V$. melanocarpum and $V$. integrifolium in Succotinus). Black-sequential fruits have non-zero transition probabilities to all color categories except blue, although these rates are very low. Black-sequential fruits are also the only color category with non-zero transition probability to yellow, which is unsurprising as there is only one modern species with yellow fruits at maturity ( $V$. amplificatum) and it appears to have evolved from a black-sequential ancestor. We note, however, that yellow-fruited forms of red-fruited Viburnum species are quite common (e.g., $V$. opulus $\mathrm{f} x a n$ thocarpa in the Opulus clade; $V$. dilatatum var. xanthocarpum and V. phlebotricum f. xanthocarpum in Succotinus; see [31]). Because seven out of the nine identified fruit color transitions occur within Nectarotinus and this ancestor is frequently reconstructed as black-synchronous, blacksynchronous shows moderate transition rates to both blue and red fruit colors. These results further emphasize the difference between black-sequential fruits, which exhibit very low rates of trait evolution, and the faster rates of evolution that occur within synchronously developing fruits.

\section{Biogeography and dispersal}

The biogeography of fruit colors relates not only to their phylogenetic history, but also to fruit traits that may facilitate dispersal. It is noteworthy that Viburnum fruits within particular biogeographic regions tend to complement one another. For example, in eastern North America, native Viburnum species include both the lipid-rich blue-fruited $V$. dentatum, the carbohydrate-rich blacksequential $V$. lantanoides, the black-synchronous $V$. acerifolium, and the red-fruited $V$. trilobum. Europe's native Viburnum flora includes a lipid-rich blue-fruited species ( $V$. tinus), a black-sequential species ( $V$. lantana), and two red-fruited species (the widespread $V$. opulus, as well as $V$. orientale in the Caucasus mountains of Georgia). Europe is missing only the blacksynchronous fruit syndrome. Asia is the center of both species and phylogenetic diversity in Viburnum, and each of the fruit syndromes is also represented in that region. Thus, across most of the biogeographic range of Viburnum, all or nearly all of the syndromes are present and often represented by multiple species.

However, two regions have unusual Viburnum color communities. In the mountains of the Neotropics, there are only two fruit color categories, black-synchronous fruits with rounded endocarps in $\sim 36$ species of the Oreinotinus clade and a single black-sequential species, $V$. elatum, in Mexico. This unusual Viburnum color community simply reflects the fact that only the Oreinotinus clade successfully radiated into the cloud forests of the Neotropics $[24,26]$. The second region with a somewhat unusual Viburnum color community is tropical Southeast Asia, which lacks a significant presence of red-fruited species. Viburnum clemensiae inhabits tropical forests in northern Borneo, and only the widespread $V$. luzonicum of the red-synchronous Succotinus clade extends south into the mountains of the Philippines. 
These fruit color communities in Viburnum have been assembled largely through the movement of clades around the Northern Hemisphere rather than through the evolution fruit colors in situ. For example, there appear to have been six movements from the Old World into North America [22]. In four of these cases, plants arrived with fruit syndromes that had evolved earlier in Asia. Members of the Lentago clade and $V$. lantanoides (Pseudotinus) retained black-sequential fruits, while $V$. edule and $V$. trilobum (two separate entries into North America within the Opulus clade) retained their ancestral red fruits. It is unclear whether the large Porphyrotinus clade entered the New World with blacksynchronous fruits or whether they evolved this fruit type upon arrival. The most interesting case in North America is $V$. acerifolium, which is descended from redfruited ancestors in the Old World (its closest relatives are $V$. orientale in the Caucusus mountains and $V$. kansuense in China). It may have evolved a black fruit color in the Old World and then become extinct there after moving to North America, but more parsimoniously it evolved black-synchronous fruits after entering North America (possibly mimicking the black fruits of Porphyrotinus species, which were already present at that time in North America). Multiple cases of dispersal to a new region followed by fruit color evolution have been documented in other angiosperms; e.g., from red to black in Gaultherieae [79] and from black to red in Empetrum [80]. Our analyses show that this has been rare in Viburnum.

Another case of convergence may relate, in quite a different way, to geography. So far as we know, no member of the Eurasian Tinus clade (with blue lipid-rich fruits) ever entered the New World, leaving room for the independent evolution of this syndrome in that region. This niche may then have been filled by $V$. dentatum, which evolved blue color in a clade that already had evolved lipid-rich fruits. Both the $V$. tinus species complex in Europe (which includes a species endemic to the Canary Islands, $V$. rugosum, and another to the Azores, $V$. treleasii), and the $V$. dentatum complex in Eastern North America, have exceptionally broad geographic ranges and large populations sizes. In both cases, it is plausible that blue lipid-rich fruits, broad geographic ranges, and large population sizes relate to dispersal by migratory bird species [33, 34, 62, 76].

Recent work on Gaultherieae [79] also addressed fruit color evolution, focusing on links between biogeography and fruit color. Their findings suggest that different fruit colors may have different propensities for dispersal, specifically that red fruits are more likely to disperse long distances and then evolve new fruit colors in situ. Unlike in Gaultherieae, we find only a single case of dispersal followed by in situ fruit color evolution, that of $V$. acerifolium (see above). However, as in Gaultherieae, it is possible that red-fruited lineages are more likely to disperse long distances than would be expected by chance. Of roughly twelve inter-continental dispersals in Viburnum [22], six of these occurred in red-fruited lineages while only a quarter of Viburnum species exhibit red fruits. Although the pattern is not as strong in $\mathrm{Vi}$ burnum as it is in Gaultherieae, it does support the notion that red fruits may undergo long distance dispersal more frequently than other fruit colors. If this is true, it may help to explain other broad spatial patterns, such as the prevalence of red fruits at high latitudes in areas that have been recently recolonized following Pleistocene glaciations [81].

\section{Conclusions}

Careful studies of the factors that underlie fruit trait diversification in particular lineages will help to advance our understanding of fruit evolution more broadly. Here, we have focused on correlated evolution between color, nutritional content, and morphology - the entire "package" that dispersers interact with. The syndromes we identify, as well as the potential significance of developmental trajectory (i.e., sequential vs. synchronous development), highlight that there are many under-explored aspects of fleshy fruit diversity. We suspect that syndromes of fruit traits, independent of the major dispersers (birds and mammals), will be found in other fleshy-fruited lineages. Viburnum fruits, with the exception of the unusual blue structural color in two lineages, are hardly unique: their nutritional contents, colors, sizes, and developmental patterns fall well within the range observed on a global scale [66]. Yet we have little reason to expect that the syndromes we have discovered in Viburnum will be identical in other lineages. If these syndromes were universal, all red fruits would have the same set of traits as red Viburnum fruits, which is clearly not the case. As we noted at the outset, correlations between color, nutritional content, and morphology differ across communities/regions [13, 18, 82]. Clearly, the scale at which syndromes are assessed is crucial: individual clades may exhibit strongly marked syndromes of fruits traits (as we have documented in Viburnum), but if these syndromes differ from one clade to another such patterns may be obscured at the community level.

The ecological and evolutionary consequences of the shift between sequential and synchronous fruit development discussed here is speculative, and it would be valuable to test this hypothesis in the many other temperate shrubs and trees that exhibit similar patterns of fruit color variability (e.g., Rubus, Ribes, Vaccinium, Cornus, etc.). Our observations in Viburnum suggest that 1) sequentially developing species might tend to be dispersed by resident birds while synchronously fruiting species 
might tend to be dispersed by flocking and/or migratory birds; 2) that synchronously fruiting species mature for short periods of time during the peak migration of birds through that region while sequentially developing species mature over longer periods of time; and 3) that synchronously developing clades exhibit faster rates of trait evolution than sequentially developing clades. These patterns may hold in other lineages and sequential versus synchronous fruit development may be a key factor underlying fruit trait diversification on a global scale.

\section{Supplementary information}

Supplementary information accompanies this paper at https://doi.org/10. 1186/s12862-019-1546-5.

Additional file 1: Table S1. Nutritional, morphological and (categorical) color data for Viburnum species, as well as accession numbers and sample sizes for each measurement. Table $\mathbf{S 2}$. Step cost matrix implemented in Mesquite to represent the paedomorphy model. Table S3. Transition rate matrices used in the ancestral state reconstruction by maximum likelihood. Table S4. Transition rates between each fruit color state as estimated by make.simmap in phytools using a symmetrical model of evolution.. Figure. S1. Species' colors plotted in tetrahedral color space according to a visual model of a UV-sensitive bird. Figure S2. Volume overlap between each fruit color category in tetrahedral color space.

\section{Abbreviations}

AICc: Akaike information criterion (corrected); ANOVA: Analysis of variance; AOAC: Association of Official Analytical Chemists; PCA: Principal components analysis; PICs: Phylogenetic independent contrasts; RAD-seq: Restriction-site associated DNA sequencing

\section{Acknowledgements}

We are immensely grateful to Paula Rudall, Beverley Glover, Pete Atkins, and Kathryn Richardson for granting access to the collections at Kew Gardens, the Cambridge University Botanic Garden, and the Arnold Arboretum, without which this work would not have been possible. We would especially like to thank Pedro Jordano for stimulating discussions on fruit ecology, as well as Walter Jetz and Rick Prum for helpful comments. Nicole Richardson provided valuable assistance in the lab, and Morgan Moeglin provided essential fruit material.

\section{Authors' contributions}

M.S.A. and M.J.D. designed the study. M.S.A. and C.L. performed laboratory work and W.C. collected endocarp shape data. M.S.A drafted the manuscript, M.S.A. and M.J.D. revised the manuscript and incorporated inputs from all authors. All authors have read and approved the manuscript.

\section{Funding}

Graduate student support was generously supplied by a National Science Foundation Graduate Research Fellowship (DGE-1122492) to M.S.A. A Yale MacMillan International Dissertation Research Fellowship, also to M.S.A., provided funding for international fieldwork. Except for generously providing the opportunity to conduct this work, funding agencies did not play a role in collection, analysis, or interpretation of data.

\section{Availability of data and materials}

All data generated in this study are made publicly available at Data Dryad: https://doi.org/10.5061/dryad.h44j0zpft.

Ethics approval and consent to participate Not applicable.

\section{Consent for publication}

Not applicable.

\section{Competing interests}

The authors' declare that they have no competing interests.

\section{Author details}

${ }^{1}$ Department of Ecology and Evolutionary Biology and Peabody Museum of Natural History, Yale University, New Haven, CT 06520, USA. ²Department of Ecology \& Evolutionary Biology, University of Colorado—Boulder, Boulder, CO 80309, USA. ${ }^{3}$ Department of Fisheries, Animal and Veterinary Sciences, University of Rhode Island, Kingston, RI 02881, USA. Department of Biology, The College of New Jersey, Ewing, NJ 08628, USA.

Received: 15 August 2019 Accepted: 21 November 2019

Published online: 13 January 2020

\section{References}

1. $\quad$ van der Pijl L. Principles of Dispersal in Higher Plants. Berlin: Springer; 1969.

2. Snow DW. Evolutionary aspects of fruit-eating by birds. Ibis. 1971; 113(March):194-202.

3. Stiles EW. The influence of pulp lipids on fruit preference by birds. In: Fleming T.H., Estrada A. (eds) Frugivory and seed dispersal: ecological and evolutionary aspects. Advances in vegetation science, vol 15. Springer, Dordrecht. 1993. https://doi.org/10.1007/978-94-011-1749-4_16.

4. Levin DA, Kerster HW. Gene flow in seed plants. Evol Biol. 1974;7:139-220.

5. Janzen $\mathrm{DH}$. Herbivores and the number of tree species in tropical forests. Am Nat [internet]. 1970;104(940):501-28 Available from: http://www. journals.uchicago.edu/doi/10.1086/282687 .

6. Schaefer HM, Ruxton GD. Plant-Animal Communication. New York: Oxford University Press; 2011.

7. Laska MS, Stiles EW, Laska MS, Stiles EW. Effects of fruit crop size on intensity of fruit removal in Viburnum prunifolium. Oikos1. 1994;69(2): 199-202.

8. Valenta K, Lehman SM. Ch. 18. Seed dispersal by mouse lemurs: Do Microcebus represent a unique frugivorous guild? The Dwarf and Mouse Lemurs of Madagascar: Biology, Behavior and Conservation Biogeography of the Cheirogaleidae. 2016. 353-365 p.

9. Janson $\mathrm{CH}$. Adaptation of fruit morphology to dispersal agents in a Neotropical forest. Science. 1983;219(4581):187-9.

10. Duan Q, Goodale E, Quan R. Bird fruit preferences match the frequency of fruit colours in tropical Asia. Sci Rep [Internet]. 2014;4:5627 Available from: http://www.pubmedcentral.nih.gov/articlerender.fcgi?artid=4102077\&tool= pmcentrez\&rendertype=abstract.

11. Willson MF, Graff DA, Whelan CJ. Color preferences of frugivorous birds in relation to the colors of fleshy fruits. Condor. 1990;92(3):545-55.

12. Valenta K, Nevo O, Chapman CA. Primate fruit color: useful concept or alluring myth? Int J Primatol. 2018;39(3):321-37.

13. Valido A, Schaefer HM, Jordano P. Colour, design and reward: phenotypic integration of fleshy fruit displays. J Evol Biol [Internet]. 2011;24(4):751-60 Available from: http://doi.wiley.com/10.1111/j.1420-9101.2010.02206.x.

14. Willson MF, Whelan CJ. The evolution of fruit color in fleshy-fruited plants. Am Nat. 1990;136(6):790.

15. Schaefer HM, McGraw K, Catoni C. Birds use fruit colour as honest signal of dietary antioxidant rewards. Funct Ecol. 2008;22(2):303-10.

16. Schaefer HM, Braun J. Reliable cues and signals of fruit quality are contingent on the habitat in black elder (Sambucus nigra). Ecology. 2009: 90(6):1564-73

17. Schaefer HM, Valido A, Jordano P. Birds see the true colours of fruits to live off the fat of the land. Proc R Soc B. 2014;281:20132516.

18. Cazetta E, Galetti M, Rezende EL, Schaefer HM. On the reliability of visual communication in vertebrate-dispersed fruits. J Ecol. 2012;100:277-86.

19. Cazetta E, Zumstein LS, Melo-Júnior TA, Galetti M. Frugivory on Margaritaria nobilis L.f. (Euphorbiaceae): poor investment and mimetism. Rev Bras Botânica [Internet]. 2008:31(2):303-8 Available from: http://www.scielo.br/ scielo.php?script=sci_arttext\&pid=S0100-84042008000200012\&lng=en\&nrm= iso\&tlng=en.

20. Stournaras KE, Prum RO, Schaefer HM. Fruit advertisement strategies in two Neotropical plant-seed disperser markets. Evol Ecol [Internet]. 2015; 29:489-509 Available from: http://link.springer.com/article/10.1007/s106 82-015-9766-7.

21. Jordano P. Diet, fruit choice and variation in body condition of frugivorous warblers in Mediterranean scrubland. Ardea. 1988;76:193-209. 
22. Landis MJ, Eaton DAR, Clement WL, Park B, Spriggs EL, Sweeney PW, et al. Joint estimation of geographic movements and biome shifts during the global diversification of Viburnum. bioRxiv. https://doi.org/10.1101/811067 .

23. Schmerler SB, Clement WL, Beaulieu JM, Chatelet DS, Sack L, Donoghue MJ, and Edwards EJ. Evolution of leaf form correlates with tropical-temperate transitions in Viburnum (Adoxaceae). Proc R Soc B. 2012;279:3905-3913. https://doi.org/10.1098/rspb.2012.1110.

24. Spriggs EL, Clement WL, Sweeney PW, Madriñán S, Edwards EJ, Donoghue MJ. Temperate radiations and dying embers of a tropical past: the diversification of Viburnum. New Phytol. 2015;207(2):340-54.

25. Edwards EJ, Chatelet DS, Chen BC, Ong JY, Tagane S, Kanemitsu H, Tagawa K, Teramoto K, Park B, Chung KF, Hu JM, Yahara T, and Donoghue MJ. Convergence, Consilience, and the Evolution of Temperate Deciduous Forests. Am Nat. 2017;190:S1,S87-S104

26. Clement WL, Arakaki M, Sweeney PW, Edwards EJ, Donoghue MJ. A chloroplast tree for Viburnum (Adoxaceae) and its implications for phylogenetic classification and character evolution. Am J Bot. 2014;101(6): $1029-49$.

27. Eaton DAR, Spriggs EL, Park B. Donoghue MJ. Misconceptions on missing data in RAD-seq phylogenetics with a deep-scale example from flowering plants. Syst Biol. 2017;66(3):399-412.

28. Winkworth RC, Donoghue MJ. Viburnum phylogeny based on combined molecular data: implications for taxonomy and biogeography. Am J Bot. 2005;92(4):653-66.

29. Jacobs B, Donoghue MJ, Bouman F, Huysmans S, Smets E. Evolution and phylogenetic importance of endocarp and seed characters in Viburnum (Adoxaceae). Int J Plant Sci. 2008;169(3):409-31.

30. McAtee WL. A review of the nearctic Viburnum. NC: Chapel Hill; 1956

31. Hara H. A revision of the Caprifoliaceae of Japan with reference to allied plants in other districts and the Adoxaceae. In: Academica Scientific Books Inc. Tokyo, Japan; 1983.

32. Clement W, Stammer TJ, Goble A, Gallagher P, Donoghue MJ. Evolution and convergence of endocarp shape in Viburnum (Adoxaceae). In prep.

33. Smith SB, DeSando SA, Pagano T. The value of native and invasive fruitbearing shrubs for migrating songbirds. Northeast Nat. 2013;20(1):171-84.

34. Smith SB, Miller AC, Merchant CR, Sankoh AF. Local site variation in stopover physiology of migrating songbirds near the south shore of Lake Ontario is linked to fruit availability and quality. Conserv Physiol. 2015;3(1):1-14.

35. Corlett RT. Characteristics of vertebrate-dispersed fruits in Hong Kong. J Trop Ecol. 1996;12(06):819.

36. Herrera CMC. Vertebrate-dispersed plants of the Iberian Peninsula: a study of fruit characteristics. Ecol Monogr. 1987;57(4):305-31.

37. Debussche M, Cortez J, Rimbault I. Variation in fleshy fruit composition in the Mediterranean region: the importance of ripening season, life-form, fruit type and geographical distribution. Oikos. 1987;49(3):244-52.

38. Debussche M, Isenmann P. Fleshy fruit characters and the choices of bird and mammal seed dispersers in a Mediterranean region. Oikos. 1989;56(3): 327-38

39. Kitamura S, Yumoto T, Poonswad P, Chuailua P, Plongmai K, Maruhashi T, et al. Interactions between fleshy fruits and frugivores in a tropical seasonal forest in Thailand. Oecologia. 2002;133(4):559-72.

40. Otani T. Seed dispersal and predation of fleshy-fruited plants by Japanese macaques in the cool temperate zone of northern Japan. 2003;156:153-6.

41. Somasundaram S, Vijayan L. Foraging ecology of the globally threatened Nilgiri wood pigeon (Columba elphinstonii) in the Western Ghats, India 2010;1(1):9-21.

42. Tsuji Y, Morimoto M. Endozoochorous seed dispersal by Japanese macaques (Macaca fuscata): effects of temporal variation in ranging and seed characteristics on seed shadows. Am J Primatol. 2016;78:185-91.

43. Maia R, Eliason CM, Bitton PP, Doucet SM, Shawkey MD. Pavo: an R package for the analysis, visualization and organization of spectral data. Methods Ecol Evol. 2013;4(10):906-13.

44. Association of Official Analytical Chemists. Official Methods of Analysis. 15th ed. Arlington, VA; 1990.

45. Lee CM, Trevino B, Chaiyawat MA. A simple and rapid solvent extraction method for determining total lipids in fish tissue. J AOAC Int. 1996;79:487-93

46. Revell $L$. Phytools: an R package for phylogenetic comparative biology (and other things). Methods Ecol Evol. 2012;3(2):217-23.

47. Revell $\amalg$. Size-correction and principal components for interspecific comparative studies. Evolution. 2009;63(12):3258-68.
48. Lord JM, Markey AS, Marshall J. Have frugivores influenced the evolution of fruit traits in New Zealand? Seed dispersal frugivory. Ecol Evol Conserv. 2002;(January):55-68.

49. Felsenstein, J. 1985. Phylogenies and the comparative method. The American Naturalist 125:1-15.

50. Paradis E, Schliep K. Ape 5.0: an environment for modern phylogenetics and evolutionary analyses in R. Bioinformatics. 2019;35(3):526-8.

51. Killip EP, Smith AC. The South American species of Viburnum. Bull Torrey Bot Club. 1931;57:245-58.

52. Killip EP, Smith AC. The genus Viburnum in northwestern South America. Bull Torrey Bot Club. 1929;56:265-74.

53. Morton CV. The Mexican and central American species of Viburnum. Contrib US Natl Herb. 1933:26:339-66.

54. Kern JH. The genus Viburnum (Caprifoliaceae) in Malaysia. Reinwardtia. 1951 1:107-70

55. Missouri Botanical Garden, Harvard University Herbaria. Flora of China [Internet]. 2008 [cited 2019 Mar 28]. Available from: http://www.efloras.org

56. Jepson Flora Project [eds.]. Jepson eFlora [Internet]. 2019 [cited 2019 Mar 28]. Available from: http://ucjeps.berkeley.edu/eflora/

57. Huelsenbeck JP, Nielsen R, Bollback JP. Stochastic mapping of morphological characters. Syst Biol. 2003;52(2):131-58.

58. Middleton R. Structural colour in fruits. Doctoral dissertation. University of Cambridge; 2019.

59. Sinnott-Armstrong, M.A. Understanding fruit color diversity: global patterns and case studies in Viburnum. Doctoral dissertation. Yale University; 2019.

60. Smith SB, McPherson KH, Backer JM, Pierce BJ, Podlesak DW, McWilliams SR. Fruit quality and consumption by songbirds during autumn migration. Wilson J Ornithol. 2007;119(3):419-28.

61. Baird JW. The selection and use of fruit by birds in an eastern forest. Wilson Bull. 1980:92(1):63-73.

62. Herrera CM. Fruit food of robins wintering in southern Spanish Mediterranean scrubland. Bird Study [Internet]. 1981;28(2):115-22 Available from: http://www.tandfonline.com/doi/full/10.1080/00063658109476711.

63. Parrish JD. Patterns of frugivory and energetic condition in Nearctic landbirds during autumn migration. The Condor. 1997;99(3): 681-697. https://doi.org/10.2307/1370480.

64. Whelan CJ, Schmidt KA, Steele BB, Quinn WJ, Dilger S. Are bird-consumed fruits complementary resources? Oikos. 1998:83(1):195-205.

65. Herrera CM. Fruit variation and competition for dispersers in natural populations of Smilax aspera. Oikos. 1981:36(1):51-8.

66. Jordano, P. Data from: Angiosperm fleshy fruits and seed dispersers: a comparative analysis of adaptation and constraints in plant-animal interactions. Dryad Dataset 2013. https://doi.org/10.5061/dryad.9tb73.

67. Jordano, Pedro, Data from: Angiosperm fleshy fruits and seed dispersers: a comparative analysis of adaptation and constraints in plant-animal interactions, Dryad, Dataset. 2013. https://doi.org/10.5061/dryad.9tb73.

68. Donoghue MJ, Bell CD, Winkworth RC. The evolution of reproductive characters in Dipsacales. Int J Plant Sci. 2003;164(April):S453-64.

69. Jones $\mathrm{E}$, Wheelwright NT. Seasonal changes in the fruits of Viburnum opulus, a fleshy-fruited temperate-zone shrub. Can J Bot. 1987;65:2291-6.

70. Witmer MC. Nutritional interactions and fruit removal: cedar waxwing consumption of Viburnum opulus fruits in spring. Ecology. 2001;82(11):3120-30

71. Willson MF, Thompson JN. Phenology and ecology of color in bird-dispersed fruits, or why some fruits are red when they are "green". Can J Bot [Internet]. 1982;60(5):701-13 Available from: http://www.nrcresearchpress.com/doi/abs/ 10.1139/b82-092\#.VFv1H_msUV9.

72. Li X, Baskin JM, Baskin CC. Contrasting dispersal phenologies in two fleshyfruited congeneric shrubs, Rhus aromatica Ait. and Rhus glabra L. (Anacardiaceae). Can J Bot. 1999;77:976-88.

73. Stapanian MA. Evolution of fruiting strategies among fleshy-fruited plant species of eastern Kansas. Ecology. 1982;63(5):1422-31.

74. Greig-Smith PW. Bicolored fruit displays and frugivorous birds: the importance of fruit quality to dispersers and seed predators. Am Nat. 1986;127(2):246-51.

75. Sargent S. Neighborhood effects on fruit removal by birds: a field experiment with Viburnum dentatum (Caprifoliaceae). Ecology. 1990;71(4):1289-98.

76. Smith AD, McWilliams SR. Fruit removal rate depends on neighborhood fruit density, frugivore abundance, and spatial context. Oecologia. 2014; 174:931-42.

77. Galetti M. Seed Dispersal of Mimetic Fruits: Parasitism, Mutualism, Aposematism or Exaptation? Seed dispersal frugivory Ecol Evol Conserv [Internet]. 2002;177-91. 
78. Stiles EW. Patterns of fruit presentation and seed dispersal in birddisseminated woody plants in the eastern deciduous forest. Am Nat. 1980; 116(5):670-88

79. Lu L, Fritsch PW, Matzke NJ, Wang H, Kron KA, Li DZ, Wiens JJ. Why is fruit colour so variable? Phylogenetic analyses reveal relationships between fruitcolour evolution, biogeography and diversification. Glob Ecol Biogeogr. 2019;28:891-903.

80. Popp M, Mirré V, Brochmann C. A single mid-Pleistocene long-distance dispersal by a bird can explain the extreme bipolar disjunction in crowberries (Empetrum). Proc Natl Acad Sci. 2011;108(16):6520-5.

81. Sinnott-Armstrong $M$, Downie $A E$, Federman $S$, Valido $A$, Jordano $P$, Donoghue MJ. Global geographic patterns in fruit colors and related traits. Glob Ecol Biogeogr. 2018;27:1339-51.

82. Jordano P. Angiosperm fleshy fruits and seed dispersers: a comparative analysis of adaptation and constraints in plant-animal interactions. Am Nat. 1995;145(2):163-91.

\section{Publisher's Note}

Springer Nature remains neutral with regard to jurisdictional claims in published maps and institutional affiliations.

Ready to submit your research? Choose BMC and benefit from:

- fast, convenient online submission

- thorough peer review by experienced researchers in your field

- rapid publication on acceptance

- support for research data, including large and complex data types

- gold Open Access which fosters wider collaboration and increased citations

- maximum visibility for your research: over $100 \mathrm{M}$ website views per year

At $\mathrm{BMC}$, research is always in progress.

Learn more biomedcentral.com/submissions 